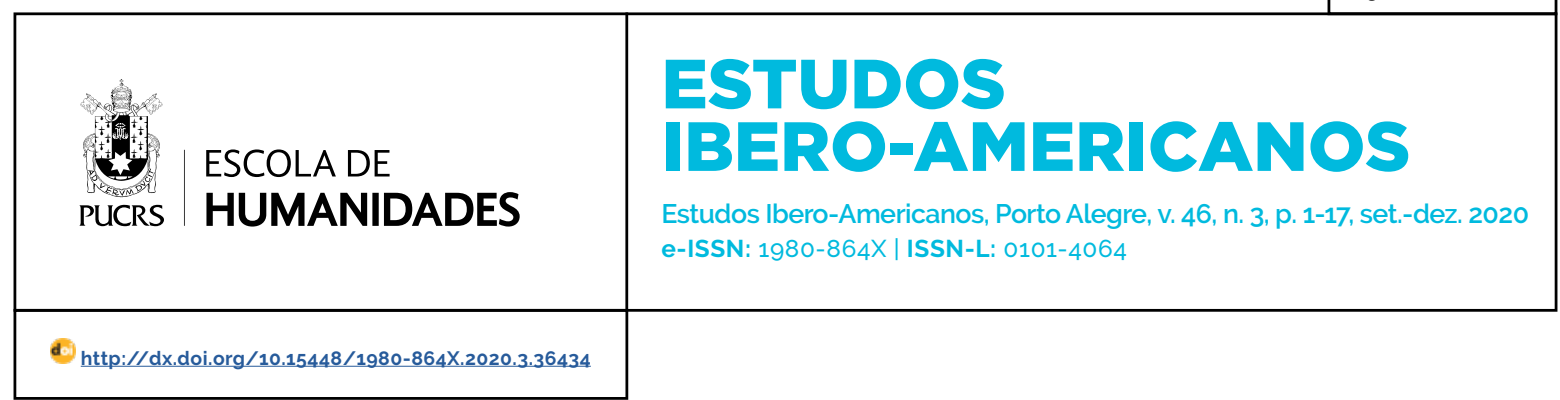

DOSSIÊ

\title{
La National Paper and Type Co. y el negocio del panamericanismo (1900-1930)
}

\author{
A National Paper and Type Co. e os negócios pan-americanos. (1900-1930) \\ The National Paper and Type Co. and the Pan American business (1900-1930)
}

\author{
Ana Maria Serna ${ }^{1}$ \\ orcid.org/0000-0001-9674-8686 \\ asernaro@gmail.com
}

Recebido em: 19 nov. 2019.

Aceito em: 16 maio 2020

Publicado em: 21 dez. 2020.
Resumen: Este trabajo aborda la historia del panamericanismo a partir del análisis de un caso particular: las actividades mercantiles y el discurso publicitario de la compañia estadounidense llamada National Paper and Type Co. Esta empresa acaparó el mercado de la exportación de maquinaria y productos para la impresión (papel y tinta) manufacturados en los Estados Unidos para distribuirlos a toda Latinoamérica. Fue la principal proveedora de los insumos con que se hicieron los periódicos más notables de la región. Al dominar este mercado, construyó el andamiaje de la estructura material de la esfera pública. Fue una activa divulgadora del discurso panamericanista para asegurarse clientes, promover una cultura de negocios en América Latina típica de la sociedad anglosajona y cultivar una mentalidad que propiciaba el consumo. Promovió la valoración de Latinoamérica y fortaleció los vínculos que proponía la utopia que imaginaba una Panamérica unida. Esta intermediaria comercial y cultural construyó un puente de comunicación que abonaría al fortalecimiento de una esfera pública transnacional.

Palabras clave: esfera pública, trasnacionalismo, prensa, panamericanismo, negocios

Resumo: Este trabalho aborda a história do pan-americanismo a partir da análise de um caso particular: as atividades comerciais e o discurso publicitário da empresa americana denominada National Paper and Type Co. Esta empresa monopolizou o nicho de mercado para exportação de máquinas e produtos para impressão (papel e tinta) fabricados nos Estados Unidos para distribuição em toda a América Latina. Foi a principal fornecedora dos insumos com os quais foram produzidos os jornais mais notáveis da região. Ao dominar esse mercado, construiu o alicerce da estrutura material da esfera pública. Foi uma disseminadora ativa do discurso pan-americano que aproveitou a oportunidade para garantir clientes, promover uma cultura de negócios na América Latina típica da sociedade anglo-saxônica e cultivar uma mentalidade que incentivava o consumo. Promoveu uma avaliação muito importante da América Latina e fortaleceu os elos propostos por essa utopia de proximidade que imaginava uma Pan-América unida. Esse intermediário comercial e cultural construiu uma ponte de comunicação que contribuiria para o fortalecimento de uma esfera pública transnacional. Palabras-chave: esfera pública, transnacionalismo, imprensa, panamericanismo, negócios

Abstract: This work addresses the history of Pan-Americanism focusing on a particular case: the commercial activities and the advertising discourse of the American company called the National Paper and Type Co. This company monopolized the exports market for printing machinery and products mainly paper and ink manufactured in the United States for distribution throughout Latin America. It was the main supplier of the raw materials with which the most prominent newspapers in the region were printed. While dominating this market, this company built the scaffolding structure of the public sphere. Was an active disseminator of the Pan-American discourse that took the opportunity to secure customers, promote a business culture in Latin America typical of Anglo-Saxon society and promoted a mentality that encouraged consumption. The kind of Pan-America-
Artigo está licenciado sob forma de uma licenç Creative Commons Atribuição 4.0 Internacional. 
nism that manipulated this company promoted a very important discourse prone to the appreciation of Latin America and strengthened the links proposed by that utopia of proximity that imagined a united Pan-America. This commercial and cultural intermediary built a communication bridge that would contribute to the strengthening of a transnational public sphere.

Keywords: public sphere, transnationalism, press, pan-Americanism, business

\section{La National Paper and Type Co. y el negocio del panamericanismo. (1900-1930). ${ }^{2}$}

Pan Americanism is an expression of the idea of internationalism. America will become the guardian of that idea, which will in the end rule the World. The policy of Pan-Americanism is practical. The Pan-American spirit is ideal. The American family of nations migth well take for its motto "One for all: all for one". The Republics of America are no longer children in the great family of nations. They have attained maturity. LANSING, Robert, (1916, p. 68)..3

La historia del panamericanismo ha sufrido de las tensiones naturales que implica un proyecto tan ambicioso como la unidad de las Américas. La utopía de unidad continental aún enfrenta obstáculos: los ataques a los migrantes, la separación de familias, los niños abandonados, el narcotráfico, el Muro de Trump y la violencia, nos obligan a repensar, una vez más, qué posibilidades tenemos y hemos tenido los americanos de unirnos en un proyecto común. Atendiendo a esa preocupación este trabajo surge del estudio de los contactos entre la América Latina y los Estados Unidos de norteamérica.

Habiendo estudiado las relaciones entre mexicanos y extranjeros en los enclaves petroleros en las épocas convulsas de la revolución mexicana de 1910, transité a la importancia de los escritos periodísticos para las relaciones diplomáticas como vehículos de la construcción y la percepción del otro en aquellos casos de encuentro donde conviven, frente a frente, americanos anglosajones y latinoamericanos. He analizado el esfuerzo de los periodistas mexicanos para influir en la opinión pública de los Estados Unidos y del resto de Latinoamérica. Coincididendo con los estudios de Catherine Legrand, Gilbert Joseph o Julio Moreno puedo argumentar que la presencia del capital y el discurso estadounidense en las economías latinoamericanas no han implicado necesariamente una resistencia local a la presencia extranjera. (LE GRAND, 1998; JOSEPH, 1998; MORENO, 2003).

En ciertos espacios de la prensa y la literatura, algunos intelectuales y políticos opusieron una resistencia discursiva al poder hegemónico de Estados Unidos en la región pero el estatus de las relaciones interamericanas depende del cristal con que se mire. Aquí propongo enfocarme en los nodos donde confluyeron relaciones comerciales y empresariales que promovieron un discurso de acercamiento panamericanista contraponiéndose al constante golpeteo discursivo que ha caracterizado a los puntos de vista más extremos de las relaciones interamericanas. Atendiendo al vínculo entre el comercio y la esfera pública para comprender la historia del panamericanismo, este trabajo contribuye a procurar un entendimiento más profundo de los procesos de construcción de una esfera pública interamericana vinculada a la historia de los negocios. ¿Qué tanto depende la esfera pública latinoamericana de Estados Unidos -me pregunto-? ¿Cómo operaron prácticas comerciales concretas y la cultura de negocios especifica del discurso panamericanista en la esfera pública trasnacional?4 (HABERMAS, 1991; PETERS, 2010, p. 237-246). Para pensar estas cuestiones me adhiero a la premisa de algunos autores que presentan el panamericanismo como un trabajo conjunto en el terreno cultural, diplomático y de los negocios que llevaría a los ciudadanos de las naciones americanas a crear una "opinión pública compartida para monitorear y guiar la politica internacional de sus naciones". (CÁNDIDA, 2017, p. 4). Se construye ahi algo similar a la esfera pública de Habermas y de Arendt

\footnotetext{
2 Este artículo se basa en el análisis de la revista El arte tipográfico dedicada a los adelantos de la imprenta y las artes gráficas: 1916 1927. (Colección Universidad de Harvard), de 17 expedientes del Tribunal Superior de Justicia del D. F. (Archivo General de la Nación, México), de las cartas de los cónsules del U.S. Department of State y la colección hemerográfica de la Universidad de Harvard.

3 "Convention week at the capital", The Independent, 10 de enero de 1916, p. 68.

4 Utilizó el concepto de esfera pública de Jürgen Habermas y de esfera pública transnacional de Peters.
} 
un espacio donde se genera el diálogo público "racioncinante", un espacio de persuasión que es la base de los procesos deliberativos. Pensadores como Peters han abierto la posibilidad de pensar en este diálogo allende las fronteras nacionales e imaginarlo como un pasaje de ida y vuelta donde fluye una conversación que trasciende a la nación. La idea de una esfera pública transnacional abre lo que la nación encierra, algo tan fluido como el discurso y el lenguaje. La esfera pública la entendemos aqui como una manifestación de lo transnacional definido por Rocco y García como: "un espacio social, esfera o campo -una comunidad de relaciones y comunicaciones- que vincula a personas, redes y organizaciones a través de los limites y las fronteras de diferentes naciones."(ROCCO Y GARCIA, 2006, p. 10) Implica, como dice Vertovec, "sistemas de vínculos sostenidos e intercambios en marcha constante entre actores no estatales a través de las fronteras nacionales -negocios, organizaciones no gubernamentales, e individuos que comparten los mismos intereses [...] A los atributos colectivos de tales conexiones, sus procesos de formación y mantenimiento, y a sus implicaciones más amplias, se les llama "transnacionalismo". (VERTOVEC, 2009. p. 14)

\section{La utopía imperialista}

El discurso panamericanista operó en el mundo de la palabra escrita con un objetivo pragmático que fue exitoso: conectó la presencia del estadounidense en la economía latinoamericana al impulso de creación de un espacio de diálogo transnacional. Como consecuencia de la revolución social que sacudió a México desde 1910 y la proliferación de movimientos y escritos en diversos paises de América Latina que advertian el imperialismo de Estados Unidos, el vecino del norte prestó oídos a la voz de los periodistas porque plumas y publicaciones fueron el vehículo principal del radicalismo revolucionario y de la propaganda que amenazaban con desestabilizar la región. Esta tensión se agravó con la primera Guerrra Mundial que agregó la presencia de las potencias a una ecuación ya de sí complicada. Como se sabe, Estados Unidos movilizó importantes recursos propagandisticos para acompañar su hegemonía en la región.

El concepto de unión panamericana presuponia la existencia de espacio comunicativo de conexión entre americanos: multilingüe y propenso a la dominación fue en el terreno periodístico internacional donde surgió un intento de interconexión. Este espacio fue posible por el vinculoentre grupos con intereses comunes. Los intelectuales, artistas, diplomáticos, académicos entre los que destacan los antropólogos, las élites favorecedoras de la idea de progreso, y los intermediarios de las compañias con intereses de expansión en diferentes regiones de América, fueron agentes que pavimentaron esta vía con espejos para mirarse y reconocerse los unos a los otros.

La historia del concepto del panamericanismo engloba definiciones y actitudes confrontadas. En las primeras tres décadas del siglo veinte, el intercambio diplómatico, comercial y cultural que pretendió crear la utópica Panamérica sufrió tensiones que se resolvieron parcialmente con el desgaste de la Primera Guerra Mundial y con la politica del buen vecino. Las actitudes cambiaron después para favorecer cierta unidad entre la América Latina y la sajona, pero se revirtieron después con la Guerra Fría o tomaron un franco cariz anticomunista. En los primeros años los debates en torno a la viabilidad del panamericanismo abundaron porque la idilica premisa de unidad nacia montada sobre evidentes paradojas. Para Woodrow Wilson la buena voluntad fraterna era el cimiento que sostenía el ideal panamericanista; sus pilares: la fe y la justicia. ${ }^{5}$ Confió este artificial abrazo al hecho de que las repúblicas americanas habian redactado sus constituciones siguiendo el molde de la constitución estadounidense. "Les hemos enseñado a aspirar al autogobierno -dijo-. Ahora vamos a enseñarles cómo usarlo. Vamos a soldar a toda América en las alianzas del panamericanismo."6 Wilson tuvo buenas intenciones pero se le atravesó el llamdo paternal

\footnotetext{
"Convention week at the Capital". The Independent, 10 de enero de 1916, p. 68.

"A new Pan Americanism", The Advance, 18 de junio de 1914, p. 1318. "Convention week at the Capital", The Independent, 10 de enero de 1916, p. 68
} 
intervencionista en varias ocasiones.

Muchos pensadores de entonces advirtieron que el panamericanismo estaba menguado de antemano por desequilibrios originarios. Para algunos, era un dique para contener la presencia europea en el continente americano, pero, al mismo tiempo, el pensamiento europeizante fungió como salvaguarda de América Latina frente a la sombra del coloso del norte que muchos intelectuales y líderes sociales como José Martí y Sandino advertirían. Por ejemplo, el presidente argentino Sáenz Peña enfatizó que el panamericanismo no implicaba debilitar los lazos de amistad que unian a América con Europa. ${ }^{7}$

Algunos analistas señalaron también que unos paises eran deudores y Estados Unidos prestamista y acreedor. ${ }^{8}$ Otros defendieron la incompatibilidad del temperamento anglosajón y aquél de las repúblicas latinas más la sospecha de estas últimas de que la cercanía con Estados Unidos podía era un peligro para su independencia. ${ }^{9}$ Se evidenció además la manifiesta desunión de las repúblicas latinoamericanas enfrentadas entre sí. De hecho, se planteó el panamericanismo como un espacio que propiciara un arreglo judicial a estas disputas.

Al discurso de aparente buena voluntad, se opusieron también el hispanismo y las nacientes apologías al mestizaje. En 1931, José Vasconcelos escribió a los estadounidense: "Si en realidad son amigables, ¿por qué no reconocer nuestra natural necesidad de combinar nuestra fuerza racial para cooperar con la gran civilización del norte como amigos y no como esclavos ${ }^{10}$ Se ha dicho que la Guerra Mundial sirivió para reforzar la solidaridad americana, pero en esos años también surgieron movimientos revolucionarios soberanistas y nacionalistas.

En 1941, el chileno Galvarino Gallardo evaluó el trabajo de los años previos:

[...] De todo lo actuado no se ha obtenido hasta el momento un gran provecho en la solida- ridad espiritual y en la buena coordinación económica, realidades ambas que merecen un apoyo cada vez mas creciente de parte de los gobernantes y legisladores continentales. ${ }^{11}$

No gastaré estas líneas en la presencia del intervencionismo yanqui en múltiples territorios de América Latina que fue dejando un rastro de dominación que chocaba con los deseos de unidad panamericana. Me concentro en los entusiastas de la Panamérica que procuraron franquear el obstáculo de la ignorancia mutua entre naciones americanas que podia resarcirse a través de la comunicación. Rescato a aquellos que manipularon el concepto de "partnership" tratando de modificar la imagen del norte como un despreciable guardián. ${ }^{12}$ Algunos prosélitos de la unidad panamericana adelgazaron el espacio que limitaba sus fronteras. Entre estos estuvieron los ejecutivos de la National.

Como parte de este fenómeno propongo historiar aqui un asunto poco atendido que fue relevante en el mundo de los intercambios comerciales concretos, de la realidad tangible de los negocios transnacionales interamericanos y su vínculo con la cultura: el espacio comercial de compra-venta de maquinaria e insumos para la edición y la impresión de periódicos y revistas que dominó hasta los años cuarenta la empresa estadounidense National Paper and Type Company. ${ }^{13}$

\section{La National Paper and Type Company: estructura material y discursiva de la esfera pública panamericana}

En 1900, la National se constituyó con el objetivo de distribuir sólo en América Latina papel, maquinaria de imprenta, tintas, tipos y toda materia prima necesaria para el trabajo de impresión de periódicos, revistas y libros. En poco tiempo controló el mercado de exportación de esos productos y fue distribuidora exclusiva de uno de los inventos más importantes de los tiempos

\footnotetext{
"Pan-American Action at Buenos Aires", Zion's Herald, 23 de agosto de 1910, p. 997

"A new Pan Americanism", The Advance, 18 de junio de 1914, p. 1318.

H. Addington Bruce, "The United States a world Power", Outlook, 3 de abril de 1909, p. 796.

Vasconcelos, "Panamericanism or Hispanoamericanism", Books Abroad, 1931, p. 437.

Mújica J., "Panamericanismo", Boletín de la Académia Chilena, 1 de enero de 1942, p. 115.

"President Wilson's Message", The Independent, 20 de diciembre de 1915, p. 461.

En adelante me referiré a esta empresa como la National.
} 
modernos: el linotipo Mergenthaler que revolucionó la industria periodistica.14 Para lograrse un mercado hizo un esfuerzo organizado para tender puentes culturales y lograr una relación cordial, refrenar el prejuicio y la desinformación. Revisando la estrategia de múltiples matices que implementó la National reconstruyo el espacio económico-discursivo en que germinó una esfera pública trasnacional panamericana. ${ }^{15}$ El fin último de semejante aproximación fue la necesidad material de propiciar la apertura de un mercado latinoamericano que consumiera la maquinaria y las manufacturas de los fabricantes de Estados Unidos, que devorara la técnica y cediera en el campo de la estética publicitaria. Gracias a este sincero y utilitario acercamiento, Estados Unidos exportó máquinas y una eficaz metodología de la administración de empresas. Paso a paso, la esfera pública latinoamericana se fue convirtiendo en un mercado y, a la vez, en el vehículo de la publicidad estadounidense. El capital del norte cerró su círculo: proveyó de los insumos materiales a la prensa del sur que serviría de escaparate para sus productos y su propaganda. Con ello logró el ascenso de una cultura del consumo que maduraría en el siglo veinte. Fomentó una buena relación de todas las Américas y abrió nichos para la hegemonía estadounidense.

La premisa empresarial de la compañia fue expandir el comercio de toda manufactura relacionada con la impresión, edición y material de escritorio, producida en los centros fabriles de la costa este de Estados Unidos. El producto que más vendia era el papel. En ese entonces, el papel impreso, era el transporte de las ideas, el cuerpo y la esencia de los libros, revistas y periódicos, la pulpa de la cultura escrita y, como consecuencia, la materia prima de la esfera pública. Tras bambalinas, la National fue proveedora de las herramientas técnicas necesarias para la prosperidad del diálogo mediático. Proveyendo de la plataforma técnica a los diarios más importantes de América Latina, ayudó a insertarlos en la modernidad de las comunicaciones y, a un mismo tiempo los volvió dependientes de esos insumos y esa tecnología de punta para la impresión. Siendo tan precarias las finanzas de los empresarios de la prensa, sobre todo de los editores independientes y las publicaciones de combate, la National y los intereses comerciales que representaba fungieron necesariamente como piezas promotoras o inhibidoras del desarrollo de la esfera pública latinoamericana. Teniendo esa importancia sociocultural, el mercado de la National fue el sustento de la estructura material de la esfera pública y contribuyó a convertir este espacio fundamental para la democracia deliberativa en un terreno fértil para el marketing de la utopia de Panamérica. Con una idea clara del rol que su negocio jugaba en el mercado y el de las culturas que crecian y se convulsionaban al sur del Río Grande, la compañia promovió y defendió los valores de un panamericanismo respetuoso para abrir un campo especifico de influencia.

La declaración de propósitos de la compañía expone los elementos, ideas y valores especíicos de este ejemplo particular del arte de la diplomacia comercial que implementó esta peculiar corporación:

Debido a que el papel y las manufacturas forman uno de nuestros más importantes artículos de comercio con América Latina (en 1918 nuestras ventas totales a esa región ascendieron a más de 20 millones de dólares) -decia su gerente- la compañia siente una responsabilidad particular de asegurar que se establezcan y se conserven las relaciones correctas [...]

El artículo que más se vende es el papel para periódicos. Con esto, la compañia está ayudando a la población a hacer uso de los vastos recursos de su territorio con la educación a través del medio de la página impresa, creando asi la demanda de noticias y más altos niveles de vida.

Cuando uno lee cualquier publicación latinoamericana, ya sea libro, revista, panfleto, catálogo o música; utiliza cuadernos en blanco, papel para escribir, sobres, papel carbón, papel para envolver, bolsas de papel, tarjetas, cajas

\footnotetext{
14 Buscando los vinculos entre periodistas mexicanos y estadounidenses encontré un punto clave para la historia del periodismo: el papel, el insumo que más codiciaban los editores de periódicos, más aún en tiempo de guerra. Como ocurría con el petróleo, las compañías productoras de esta materia prima, fueron grandes beneficiarias de esa lucha armada. Entre las compañias productoras de papel, la que más he podido documentar hasta ahora es la National que sirve además como un ejemplo de las estrategias implementadas en la práctica comercial tangible que estructura una cultura de negocios específica bajo los lineamientos del discurso panamericanista.

15 "Some Pan-American Problems", The New York Times, 23 de julio de 1922, p. 50.
} 
de cartón, servilletas y toallas de papel; firma un cheque o nota, un pagaré o una hipoteca; maneja notas bancarias, acciones o bonos; decora las paredes con adornos de papel; juega baraja o emplea el papel de cualquier manera en América Latina, está en contacto con los productos de nuestras fábricas de papel. También con la tinta que va en ese papel, los lápices y las cintas para la máquina de escribir. Mucho de todo lo que ayuda a educar al latinoamereicano viene de los Estados Unidos y es la mercancia que maneja nuestra compañia. [...]

El poder adquisitivo de América Latina es grande y está en constante crecimiento. El comercio con esta región siempre ha creado mucho interés entre los productores y exportadores norteamericanos. [...] Estos indios y mestizos están siendo educados rapidamente por medio de la imprenta y en este proceso la compañia es, al mismo tiempo benefactora y proveedora de mercancias. (A CHAPTER IN THE ROMANCE, 1921, p. 22-23).

El dominio que ejerció la National sobre el circuito de exportación y distribución de papel y maquinaria para impresión se vinculó a la manipulación del discurso de los periódicos latinoamericanos a favor de un punto de vista que beneficiara la imagen y los intereses de Estados Unidos en la prensa y la opinión pública latinoamericanas. La National logró establecer un negocio lucrativo que caminó de la mano de un proyecto cultural conjunto de acercamiento. Abrió un inmenso mercado para sus productos, pero al hacerlo, no invadió para dominar, no pisoteó con la bota del Tío Sam a la población de América Latina. No logró vencer el complejo paternalista, pero tejió un reconocimiento dignificado de la cultura latinoamericana y los progresos económicos de la región.

Durante cuatro décadas, la National vendió a los empresarios latinoamericanos linotipos Mergenthaler, prensas para impresión de la Chandler Co., lápices de la Joseph Dixon Crucible, Co., máquinas de coser de la Boston Wire Stitcher Co., variados productos de papeleria de la Richmond Paper Manufacturing Co. y la Eaton, Crane \& Pike Co., cortadoras de papel de la The Challenge Machinery Company, mantillas de la New England Newspaper Supply Co., calentadores eléctricos para estampar en relieve y toda clase de artículos para oficina, tintas, engrudos, sacatintas y papel carbón de la S.S. Stafford, Inc.

La National construyó los cimientos con los cuales se desarrolló la estructura física y técnica de la esfera pública latinoamericana haciendo una apolgía lírica del maquinismo. El poema titulado "Soy la Prensa Tipográfica" de Roberto H. Davis publicado en una revista de la compañía advierte este impulso que, como muestran Peter Burke y Asa Briggs, (BURKE Y BRIGGS, 2006) dieron las máquinas del siglo veinte a la comunicación. Esta pujante mística sería el credo de la compañEstos aper Manufacturing Co.panye la cultura latinoamericanay los ps Estdos Unidos adornos de papelía.

\footnotetext{
Entretejo en la urdimbre del pasado la trama del porvenir. Cuento los relatos de la paz tanto como las crónicas de la guerra. [...]

Soy el incansable clarin noticiero. Pregono las alegrias y los dolores de la humanidad, hora tras hora.

Soy luz, ciencia y poder. Compendio los triunfos del cerebro sobre la materia.

Soy la crónica de cuanto la humanidad ha realizado. ${ }^{16}$
}

Con estos insumos, apoyaron el crecimiento del periodismo moderno que, como se decía en aquella época, era "antorcha del progreso en el Panamericanismo". Ambos se entrelazaban en la puesta en escena de un mecanismo civilizatorio. A este ejercicio de equilibrio que era el centro de toda sociedad democrática contribuian también las agencias estadounidenses de noticias que incrementaron el caudal de información que circulaban en el continente.

La importancia de este ensanche del servicio
-se decia- es incalculable. Significa mejor in-
teligencia y mayor amistad. Los portadores de
luz que fueron causa de este adelanto, Melville
Stone, de la Prensa Asociada y Roy Howard, de
la Prensa Unida, están echando por cimientos
de la buena voluntad panamericana los úni-
cos sobre los cuales puede ésta levantarse,
sobrevivir y desarrollarse: los de una buena
inteligencia entre los interesados. ${ }^{17}$

Tales adelantos tecnológicos y el desarrollo industrial que fue proliferando se pusieron al ser- 
vicio de una estrategia de conocimiento mutuo. Algunos detractores acusaron a estas agencias de fungir como notorios aparatos de resonancia de la propaganda yanqui y actuar como filtros nefastos que permeaban el conocimiento de las naciones latinoamericanas entre sí. Con todo, el "cable" fue una herramienta fundamental para el florecimiento de un espacio de conjunción de noticias, intereses y acercamiento entre culturas: una vía de diálogo transnacional que comenzó a resolver la problemática proliferación del prejuicio. Tiempo atrás, antes de tales avances, insistían los procuradores del panamericanismo, era dificil formarse una idea exacta de las cosas y las agencias vinieron a resarcir ese vacio. Mal que bien, se fue construyendo esa esfera pública que mientras transmitió un mensaje panamericanista, también propició un canal para difundir el fervor hispanista y consignas revolucionarias, antiyanquis y nacionalistas de caudillos rebeldes y lideres sociales latinoamericanos.

Un sintoma entre otros, de este intercambio, fue la aparición de secciones de reconocimiento bilateral en los periódicos estadounidenses como el New York Sun que publicaba los lunes tres páginas tituladas "Latin American Section", el New York Herald, el Philadelphia Public Ledger abrieron también secciones para publicar noticias y artículos ilustrados referentes a las repúblicas latinoamericanas: ${ }^{18}$

Estos artículos más detallados y desarrollados, encaminados a completar las noticias que llegan cada día por cable-decia una publicación de entonces-, le dan a este país mayor caudal de conocimientos de los intereses, esperanzas y adelantos de la América Latina que el que jamás tuviéramos anteriormente. ${ }^{19}$

La National contribuyó a este diálogo con dos revistas que nos sirven como la principal materia prima de este ensayo: El Arte Tipográfico y El Escritorio. Pasados cien años, son una fuente para la historia de la prensa, el periodismo y la industria bibliográfica latinoamericanas y de los intercambios comerciales panamericanistas. ${ }^{20}$
En ellas publicaba notas sobre Latinoamérica, exaltando su potencial cultural y económico. Celebraba, por ejemplo, el ascenso de la ganadería brasileña, las inversiones en terrenos petroliferos mexicanos, o el avance de la industria de carbón en Chile. Como contraparte, las publicaciones latinoamericanas hicieron también un esfuerzo por abrirse al mundo. Entre los que procuraron esta conversación desde el sur estaban el Jornal do Comércio de Río de Janeiro, La Nación y La Prensa de Buenos Aires, El Mercurio de Santiago de Chile, El Mundo de la Habana, El Heraldo de México, El Universal de la Ciudad de México.. Todos eran clientes de la National.

Como vemos, el trabajo internacional de la compañía la transformó en un puente cultural. Siendo el corazón de su mercado los impresos latinoamericanos, se reseñaban en El Arte Tipográfico las novedades editoriales y los impulsos al mundo de la cultura escrita en América Latina, y todo aquello de interés sobre la región que se publicaba en territorio estadounidense. La National interpretó el panamericanismo como un flujo de ida y vuelta que afectaba a la cultura material, pero sobre todo la cultura escrita. Esta influencia implicó un esfuerzo de traducción e intercambio de bienes y valores culturales. Pretendió acercar a sus clientes latinoamericanos con Estados Unidos y se asomó hasta los rincones remotos de la América para conectar los hilos de la comunicación. La compañia logró muy bien lo que, en el lenguaje de negocios se llama ciclo de reforzamiento positivo: la venta de maquinaria para impresión provocó el crecimiento de las publicaciones. Éstas abrieron espacios para la publicidad, fomentando la venta de mercancias estadounidenses. Al mismo tiempo fomentó la factura de periódicos modernos que propiciarian la prosperidad económica con información y anuncios.

El periodismo moderno, aquella práctica de informar que se desarrolló a finales del siglo diecinueve, es en realidad, "el periodismo al estilo americano", aquel que se dice imparcial y privi-

\footnotetext{
"Fomento de las Relaciones de Amistad", El arte tipográfico, septiembre, 1919, p. 106.

"El Periodismo es antorcha del progreso", El arte tipográfico, septiembre, 1919, p. 68.

"Fomento de las Relaciones de Amistad", El arte tipográfico, septiembre, 1919, p. 106.

"El Periodismo es antorcha del progreso", El arte tipográfico, septiembre, 1919, p. 68.
} 
legia la noticia sobre la opinión, que no muestra una bandera política e introduce la entrevista, el reportaje, las fotografías e ilustraciones como elementos esenciales de la propuesta editorial. Es la prensa de gran formato, grandes tirajes y ediciones que abaratan el costo de cada ejemplar para enganchar a un público amplio.

Será maestro en los periódicos -recomendaba la National- quien refiera mejor los acontecimientos, quien con más atractivos presente los sucesos que conmueven, espantan, deleitan, divierten, animan o ensombrecen la vida. Contar bien es el arte supremo del periodista; contarlo todo de tal suerte que no quede ningún pormenor en el tintero, pero sin que salga del tintero nada que ofenda, contrarie, disguste o humille al lector. ${ }^{22}$

Los periódicos modernos que comenzaron a trabajar con maquinaria de punta como las rápidas prensas y el linotipo. Los propietarios de estas grandes empresas periodisticas consideraban que la información era un bien con el que se podía lucrar y los diarios se concibieron como negocio. En las primeras décadas del siglo veinte muchos diarios latinoamericanos adoptaron estas premisas comerciales, pero convivieron con sectores de la sociedad altamente politizados que veian a la prensa como vehículo del compromiso político y con una función social: combatir a las tiranías. Curiosamente, estos fueron también clientes de la National.

El crecimiento del mercado de la National se basó en asegurar el éxito comercial de los impresores y propietarios de periódicos en América Latina que eran potenciales vendedores de publicidad y, a su vez, beneficiarian a otras empresas estadounidenses. También estuvo cimentado en la capacidad de cerrar eficazmente el proceso de transferencia de tecnología y capacitación que, en aquel entonces se hacía por medio de materiales impresos. Para fortalecer esta conexión, la National optó por la vía didáctica, la ruta civilizatoria de educar, a través de todos los medios que tenía a la mano, a operarios, gerentes y dueños para enseñarles a manejar la maquinaria que se les vendia y adoctrinarlos en torno a sus múltiples ventajas. En esta intención pedagógica utilizó la publicidad como herramienta.

La National adoptó y celebró en sus anuncios los avances de la ciencia para ponerlos al servicio de los negocios y la industria modernos. Los productos de las fábricas que distribuia, como por ejemplo, el papel esmaltado Snowflake, se publicitaban como artículos que producian "con los más científicos procedimientos, bajo la dirección de expertos". 23 Esto acarreó naturalmente una apología del maquinismo que fue ganando terreno también en los países de América Latina. La prensa "Chandler \& Price", se anunciaba con una carta de un satisfecho cliente de Colombia que la llamó "La Reina de mis máquinas", era famosa por su capacidad de imprimir 5,800 ejemplares por hora y la rápida cosedora "Boston", más que una máquina - se anunciaba - , era una fiel compañera. En esa misma lógica, se celebró el progreso tecnológico en los diarios del sur como un paso hacia la modernidad que dotaría de calidad gráfica a ese diálogo panamericano que se iria fortaleciento en el siglo veinte. ${ }^{24}$ Don Julián Ramos Peñasco, por ejemplo, fue reconocido como el responsable, teniendo a su cargo la dirección de fotograbado del Diario Ilustrado de Santiago de Chile, de lograr que éste fuera el primer periódico en Chile de informar gráficamente al público de los sucesos diarios de la capital y las provincias. El Sur de Concepción, Chile, impreso en colores, tambièn se festejó

\footnotetext{
22 "El Periodismo es antorcha del progreso", El arte tipográfico, septiembre, 1919, p. 69

23 "El triunfo de un papel", El arte tipográfico, marzo, 1918, p. 248.

24 La maquinaria que anunciaba la National Paper and Type, pertenecian a las siguientes empresas: Oswego Machine Works, The Parker Pen Co. Esterbrook Steel Pen Mfg. Co., Duplex Printing Press Co., Hamilton Manufacturing Co., Babcock Printing Press Mfg. Co., Chandley \& Price Co., H. B. Rouse \& Co., Acme Staple Co. Ldt., American Steel \& Copper Plate Co., Eaton, Crane \& Pike Co., Joseph Dixon Crucible. Co., Bingham Brothers Co., Sterling Engraving Co., Eclipse Folding Machine Co., S. D. Warren \& Co., F. P. Rosback Co., Modern Die \& Plate Press Manufacturing Co., Mohr Lino-Saw Co., Golding Press Division, Seybol Machine Co., Harris Offset Presses, Boston Wire Stitcher Co. Margach Manufacturing Co., New England Newspaper Supply Co., Mergenthaler Linotype Co., Ludlow Typograph Co., Thomson-National Press Co., Stokes \& Smith Co., Southworth Machine Co., F. L Smith Machine Co., Inc. Richmond Paper Manufacturing Co., Stafford's Commercial writhing Fluid, Eaton, Crane \& Pike Co., Gane Brothers Co., Geo H. Morrill Co., The Holliston Mills, Barton Manufacturing Co. E. W. Blatchford Co., The Challenge Machinery Co., R. H. Smith MFG. Co., Wetter Numbering Machine Co., National Machine Co., National Brand de Foyer Co., John Hope \& Sons., T. Riessner, Canadian Export Paper Co., veáse, El arte tipográfico, septiembre, 1919, p. 1 y El arte tipográfico, diciembre, 1917, p. 160.
} 
como "prueba de las espléndidas condiciones impresoras de la rotativa Duplex Tubular. ${ }^{25}$

\section{El arte de la diplomacia comercial panamericanista: un proyecto civilizatorio}

Para lograr su objetivo, la National utilizó una metodología de trabajo eficaz: entender a su cliente y convertirlo en un amigo. "[...] La compañía tiene la firme creencia -decian sus documentosque la mejor base de un negocio es la amistad. ${ }^{26}$ Siempre hay que estudiar lo que piensa el parroquiano, sus ideas y prejuicios. El cliente es lo primero". El cliente latinoamericano de la National estaba bien definido. Era una élite de propietarios de periódicos, revistas, imprentas y casas editoras que viajaba con frecuencia a Estados Unidos, para llevar de vuelta "nuevas semillas de adelanto". La National lo estudió y lo entendió bien. ${ }^{27}$ Esto se hizo con respeto y un conocimiento poco común de los asuntos y las culturas latinoamericanos. "La National -declaraban sus directivos- es el nombre de un grupo de personas vivamente interesadas en la vida y el bienestar de la América Latina". ${ }^{28}$ Desarrolló una táctica de aproximación que vinculó los confines de Estados Unidos con los extremos geográficos más distantes de la América hispanoparlante y brasileña. Reconocer al otro, conocerlo y celebrar sus bondades, fue su principal estrategia de marketing. Pecó quizás de un exagerado uso del recurso de estereotipar lo bueno y conveniente para hacer fructificar los vínculos comerciales, pero avanzó en relación con el discurso de otros tiempos al posicionar al latinoamericano en la categoria de "cliente":

El espiritu creciente del panamericanismo -explicaba una publicación conmemorativa de la empresa en 1921- está predisponiendo cada día a los pueblos latinoamericanos más y más a apoyar todo esfuerzo que nosotros en Norteamérica hacemos para mejorar nuestras relaciones con ellos. Ellos entienden los principios económicos subyacentes que están involucrados y están muy conscientes de las ventajas mutuas que resultarán de una relación más cercana. La experiencia de esta compañia es que un trato justo y la generosidad de nuestro propósito ha provocado que den la bienvenida a comerciantes de los Estados Unidos donde esos ideales han existido. Los latinoamericanos son rápidos para reconocer el valor de nuestros mejorados métodos mecánicos y de tomar ventaja de nuestra experiencia. Son ávidos compradores de toda clase de aparatos que ayudan a ahorrar trabajo. Son rápidos para detectar cualquier cosa que indica falta de la debida consideración o un mero deseo de explotación egoísta. Nunca abandonan a un amigo. (A CHAPTER IN THE ROMANCE, 1921, p. 27).

Aunque esta definición positiva de la perspicacia del hispanoamericano se construyó ad-hoc para los fines de seducción publicitaria y comercial, surge de una esencia diferente. Con esta actitud, la National coincidia con el discurso democratizante de W. Wilson que, por esas mismas épocas, se disculpaba ante América Latina por un pasado intervencionista, esforzándose para recuperar la confianza de sus vecinos y hacerse de aliados.

25 "Anuncio de Prensa Duplex, El arte tipográfico, octubre, 1919, p. 112.

26 "Lectores, clientes y amigos", El arte tipográfico, enero, 1918, p. 161.

27 Algunos clientes de la National Paper fueron: Argentina Imprenta y Papelería, El Diario Nacional, El Diario de Pernambuco, El Imparcial, La Razón, La Prensa, Plus Ultra: La Nueva Revista, El Hogar, La Palabra de Mendoza, Crítica, El Eco de España, La Opinión, Los Principios, Revista de Economia y Finanzas, El Avisador Mercantil, La Palestra, El Semanario, El Zoófilo Argentino, Caras y Caretas, Fray Mocho, Boletin de la Unión Industrial Argentina, Anales Gráficos, Páginas Gráficas, Boletín de la Sociedad Tipográfica Bonaerense, El Comentario, Revista Técnica Ferroviaria, Impresa Oficial, A Provincia, Jornal Baptista, España Nueva, Tribuna Religiosa, Liga Maritima Brazileira, Ave Maria, A Palabra, A Hora, Diario Oficial, La Patria, El Diario Nacional, El Nuevo Tiempo, El Espectador, Mundo al día, Diario Oficial, Gaceta Judicial, Revista Postal, El Evangelista Cristiano, Cromos, Cauca Comercial, Correo de Cauca, Ecos de la Montaña, Jacobo Paniagua y Hermano. Impresores, El Trabajo, El Anunciador, El Sol, La Unidad Católica, La Información, Croquis, La Temperancia, Imprenta y Libreria Alsina, El Renacimiento, Almacenes Fin de Siglo, El Progreso de Nipe, La Voz del Pueblo, Labor Sana, El Mundo, Las Guasimas, El Palenque Masónico, Memorándum Tipográfico, Pro Vida, Algo de Todo, Mercurio, El Figaro, Cuba Intelectual, Orto, La Independencia, Social, (Revista), Diario Ilustrado, El Sur, El Comercio, Zigzag, Boletín de la Unión de Fomento Fabril, Sucesos, El Comercio Ecuatoriano, Casa Colorada, El Guatemalteco, El Nacional, Revista, Centroamérica, La Juventud Centroamericana, Boletín de la Sección de Fomento, Atlántica, Le Quotidien, Revista "California", Boletín Oficial. Semana Crónica, La Academia. Imprenta y Papeleria, La Helvitia. Papelerí, El Faro, Boletín Oficial, El Nacional, El Pueblo, El Demócrata, El Universal, Petróleo, Revista del Ejército y Marina, Revista de Revistas, El Universal Ilustrado, El Progreso, La Opinión, La Prensa, La Tribuna La Antorcha, Plus Ultra, Tampico Times, Star \& Herald, El Agricultor, El Nacional, La Reforma, Industria, El Pan del Alma, La Crónica, La Prensa, Mercurio, El Perú, La Mujer Peruana, El Comercio. Diario del Oeste, La Revista Blanca, Puerto Rico Evangélico, La Conciencia Libre, La Prudencia. Sociedad Cooperativa de Crédito y Ahorro, El Mundo. Diario de la Mañana, Revista Puerto Rico Evangélico, Boletín de la Cámara de Comercio, Agricultura e Industria, Las Noticias. Heraldo Comercial, La Primada de América, El Listín Diario. La Nación, Tipografía "La Unión", La Prensa, Actualidades, El Libro Rosado de El Salvador, Diario Oficial, Diario del Salvador, Diario Latino, El Demócrata, El Cronista, El Eco Obrero, Casa Binardell Roig, Diario del Plata, Tribuna, El Heraldo Industrial, El Nuevo Diario, El Luchador, Panorama, Caracteres, Estrella de la Mañana, El Esfuerzo Médico, El Figaro, Horizontes, El Universal. Esta lista se basa en la revisión de la revista El arte tipográfico. Revista mensual dedicada al adelanto de la imprenta y las artes gráficas en general, años, 1916-1927.

28 "Lectores, clientes y amigos", El arte tipográfico, enero, 1918, p. 161 
Otro elemento de la pericia mercadológica de la National fue su buen uso del idioma español. Con todo esto estableció un contacto duradero que fortaleció, en un nodo de poder bien entretejido, las relaciones entre las Américas a partir de un vínculo bilateral de las élites. Cultivó la deferencia, las relaciones personales con aquellos empresarios pudientes de la otra América, con las "buenas familias" que gozaban de prestigio, aquellos "buenos" clientes cercanos anímicamente al progreso estadounidense y a la modernidad del desarrollo que marcaban el maquinismo, los avances de la ciencia y la técnica. El panamericanismo prosperó en esos nexos interélite donde se conectaron, gracias a los servicios de la National, algún pequeño fabricante de Winsconsin y algún acaudalado empresario colombiano. ${ }^{29}$

El panamericanismo de la National, compartido por sus proveedores y quizás de algunos de sus clientes, era conservador. La National se manifestó en varios artículos de su revista a favor de la capacitación de los operarios, pero en contra de la propaganda bolchevista y las exigencias de los extremistas que podrian llevar a la quiebra a los propietarios de empresas que estaban "dispuestos a hacerlo todo por la equidad y la justicia, pero que no consienten en pagar tributo a un grupo de sujetos cuyo único deseo es destruir el edificio social hasta sus cimientos y dar al traste con el comercio, la industria y lo demás."30

El ideal del trabajador panamericanista que exaltaba el credo de la National soñaba con un sujeto dócil: "El muchacho que llega al taller con puntualidad todos los días y hace todo lo que se le manda -se leía en el artículo titulado "La puntualidad"- cuando sea regente, o quizá dueño de una imprenta, su palabra valdrá tanto como sus demás habilidades". ${ }^{31}$ Había que domarlo con la disciplina propia de una empresa civilizada y productiva. En esa visión artificial del futuro de un aprendiz de imprenta, más equiparable con una película de Chaplin que con la dolorosa realidad del común de los trabajadores latinoamericanos y estadounidenses de aquel entonces, el trabajador se describia como un muchacho que escucha atentamente y pregunta cuando no entiende. Tenía que ser limpio, "cuyas uñas no tengan luto', habria de moverse rápida y silenciosamente, ser alegre y nunca huraño, respetuoso, que no fume, que no abuse de otros, que hable con la frente alta y diga la verdad, "que prefiera perder su colocación que decir mentiras". 32

Las prácticas de negocios y las estrategias publicitarias de la National son centrales para entender cómo el discurso panamericanista procuró, en el terreno de lo cotidiano, un encuentro cultural que fue un intento de traducción y transferencia de valores. Los representantes de la compañía expresaron un dogma mercantil para crear un mercado consumidor en América Latina, descubrieron el poder adquisitivo de la masa territorial que yacía a sus pies, pero se acercaron con genuino interés a este cliente real y siempre potencial.

La National estableció sucursales y agencias en las ciudades más importantes de América Latina como parte de su objetivo expreso de "Llegar a ser parte integral de la vida nacional de los países hispanoamericanos".33 "Somos Uno de Ustedes" decian - sus anuncios. Sus directores expresaron el deseo de que la empresa se le conociese por conducto de sus viajantes, personalmente. Las sucursales hacian las veces de misiones diplomáticas estaban bien abastecidas y pusieron la mercancía a la disposición más inmediata posible de los clientes. El personal que trabajaba en estos establecimientos eran estadounidenses versados en el idioma local y conocian los lugares y regiones a dónde se les asignaba trabajar. Pasaban por un proceso de pasantias y entrenamiento para conocer al dedillo las mercancías que vendian y, lo más

\footnotetext{
"Las cuatro PPPP", El arte tipográfico, julio, 1919 , p. 33.

"La huelga de los operarios", El arte tipográfico, octubre, 1919, p. 97.

"La puntualidad", El arte tipográfico, febrero, 1916, p. 235

"Se necesita un muchacho", El arte tipográfico, febrero, 1916, p. 236.

La National tenía sucursales en: Argentina (Buenos Aires y Rosario), Cuba (Habana), México (Ciudad de México, Tampico, Guadalajara Monterrey y Mazatlán), Perú (Lima) y Uruguay (Montevideo) y agencias en: Colombia (Bogotá y Medellín), Costa Rica (San José), Guatemala (Guatemala), Haití, (Port-au-Prince), Puerto Rico (San Juan), Venezuela (Caracas y Maracaibo), Brasil (Salvador). El arte tipográfico, septiembre de 1919
} 
importante, "tenían un conocimiento íntimo -decía la gerencia de la National- de la psicología de la gente con la que estaban tratando". (A CHAPTER IN THE ROMANCE, 1921, p. 27).

Las historias de vida de los personajes que trabajaron en esas sucursales que parecen tomadas de las novelas de B. Traven. Un caso particularmente singular es el de George C. Cobean, una especie de Indiana Jones de los negocios, que fue asignado a la sucursal de la Habana. Desde que nació, narra la semblanza de Cobean, estuvo en contacto con hispanohablantes en Nuevo México y dominaba el castellano mejor que el inglés. Conocía personalmente al general Pershing, su familia había combatido a Gerónimo el gran jefe de los Apaches y, desde su juventud, Cobean se ganó la vida trabajando en múltiples oficios en el mundo de la prensa que lo llevaron a ser reclutado como parte de las huestes comerciales de la National.

Como se ha dicho, la National también echó mano de la poderosa lengua de Cervantes y para lograr sus fines comerciales, editó y circuló en América Latina varias publicaciones. ${ }^{34}$ Estas revistas estaban redactadas en un castellano pulcro con colaboradores de un alto nivel intelectual. Las revistas de la National eran guias prácticas para impresores que hablaban principalmente de las ventajas del equipo que la empresa exportaba. Abarcaban con riqueza técnica todo lo que se quisiera saber del mundo del impreso: métodos y consejos para dueños y empleados de imprentas y publicaciones.

Publicó además el Método práctico de inglés, del profesor Alfredo Elías atendiendo a la petición de cartas que recibía con frecuencia de "personas residentes en varias repúblicas de la América hispana que, deseosas de visitar los Estados Unidos o de entablar relaciones comerciales con este país, pedian que se les recomendase un método para aprender el inglés de la manera más práctica y eficaz posible". (ELÍAS, 1930) Este libro, que logró múltiples reediciones, tuvo como objetivo enseñar el idioma inglés de manera que los hombres de negocios contaran con los fundamentos del mismo, para triunfar en sus relaciones de la vida diaria y del comercio. Esta enseñanza práctica del inglés asimiló la modernidad del panamericanismo: utilizar un método avanzado, pragmático y rápido para romper las barreras que dividian al mundo anglosajón y su intromisión imperialista de los espacios de hermandad americana.

Gracias a información diversa que arrojan los documentos relativos a la National podemos rescatar otro eje a través del cual, la cultura escrita contribuyó al reconocimiento mutuo entre naciones que implicaba un proyecto panamericanista. El Arte Tipográfico destinó una sección bibliográfica para reseñar aquellos libros que se publicaban en Estados Unidos o en cualquier república latinoamericana con una temática que allanara este camino hacia la cordialidad. Estas reseñas fueron una pieza más de aquel arte de la diplomacia panamericanista. Eran textos críticos, bien escritas y respetuosos de los escritos que analizaban que se dieron a la tarea de construir un retrato positivo de las naciones hispanohablantes. Por ejemplo, el comentario del libro The South American Republics de Thomas C. Dawson, destacaba que aquel libro contribuía con demostrar que el militarismo iba desapareciendo de Latinoamérica y cundia un deseo entre todas las clases sociales de lograr una libertad "ordenada". Acentuaba que las capacidades civicas iban aumentando entre las masas sudamericanas porque la inmigración estaba levantando el nivel de la actividad industrial.

Todas estas repúblicas -insitió la reseña- están
realizando lenta, pero segura evolución hacia
la forma de gobierno más en armonía con sus
necesidades y circunstancias propias, y un ciu-
dadano de los Estados Unidos no puede menos
que alegrarse al comprobar que dicha forma
es y permanecerá seguramente republicana. ${ }^{35}$

Otra glosa de Historia Diplomática Latinoamericana de Vicente G. Quesada, señala que la virtud de aquella novedad editorial era mostrar que "esas repúblicas que suelen ser representadas como 'terrenos de cultivo' de microbios y bacilos revolucionarios, son los estados que hasta la 
fecha han dado los más hermosos ejemplos de conciliación". ${ }^{6}$ Siguiendo este criterio, la revista Cultura Venezolana se equiparó dignamente con sus pares publicados en otros países, tales como la Revue des deux Mondes, de Paris, The Atlantic Magazine, de Boston, Harper's, de Nueva York, Nosotros, de Buenos Aires, Cuba Intelectual, de la Habana y La Lectura, de Madrid. ${ }^{37}$

Se reseñaron textos que propiciaban un conocimiento profesional del otro valorando el uso de las fuentes y el trabajo con datos fidedignos sobre la región. El desarrollo de esta literatura que iba creciendo en la América del Norte, "era señal -según los editores- de la amistad siempre creciente y sincera que va uniendo a ambas Américas con lazos más y más estrechos". ${ }^{38} \mathrm{El}$ ejercicio de redacción de reseñas críticas abonó a la intención de ciertos sectores de la sociedad estadounidense de construir un acervo de información estratégica sobre América Latina para controlar su mercado y sus manifestiaciones políticas, al son de un interés enciclopédico, pero, sin duda, abrió también un genuino interés de los académicos y las universidades que, a lo largo del siglo veinte, incrementaron el esfuerzo por inclinarse a comprender la problemática latinoamericana. Es, en resumen, lo que Cándida observa como un intercambo cultural que crea espacios de experiencia, "campos de oportunidad" donde ciertos grupos tratan de labrar un futuro más promisorio para la interrelación de naciones. (CÁNDIDA, 2017, p. 7.) Esto es precisamente lo que hemos descrito como esfera pública transnacional. El discurso panamericanista vinculado a los negocios que alimentaban con materia prima a los periódicos y revistas provocaron ese proceso de contrucción de aquel fenómeno variado que se ha descrito como transnacionalismo que, como indican Rocco y Garcia,"abarca procesos de hibridación cultural, ideológica y emocional que alimentan nuevas identidades [...]; la revolución tecnológica que facilita el transporte y la comu- nicación mientras da lugar, simultáneamente al consumo mediático mundial que, a su vez, facilita el sincretismo cultural; las redes que permiten el flujo de capital y el movimiento de las grandes corporaciones mundiales. (ROCCO Y GARCÍA, 2006, p. 14) Fomentaron un diálogo basado en el conocimiento que superó al menos discrusivamente el empuje imperialista.

En la bibliografía reseñada cundió la admiración por Bolivar, la mención a hombres notables en la ciencias y las letras. Para fomentar la cercanía se habló de las guías para viajeros como la Terry's Guide to Cuba que en 470 páginas aquilataba a la isla como destino turístico. La reseña apunta a la novedad de la aparición de estos espacios geográficos subdesarrollados en el radar del vacacionista "las guías se escriben para los turistas, y estos no solian acudir en bandadas, explicó la reseña, a los países hispanoamericanos".39

Esta particular manifestación de la cultura escrita, la literatura para viajeros, convertía las repúblicas bananeras en paraísos tropicales para el descanso. Un encantador ejemplo es la apreciación del libro Rainbow Countries of Central America de Wallace Thompson, que dice: "es verdad que Costa Rica y su tierra rojiza, Nicaragua, la de anaranjadas auroras, Honduras, con sus amarillas colinas, El Salvador y sus verdes valles y Guatemala con sus azules jardines, dan al viajero la impresión del arco iris [...]. De la América Central no se han ocupado debidamente los escritores de Norteamérica y Thompson subsana en gran medida el descuido".40 La reseña del libro Bajo el Sol de España publicado en puerto Rico, celebró la alegre religiosidad de la Semana Santa ibérica exaltando la barroca y abrumadora profundidad de la cultura de un tipo de panamericanismo hispanista: "[...] los oles con que responde la muchedumbre -dice-, el fausto de las casullas de los sacerdotes, la brillantez de los uniformes de la oficialidad, la belleza de las músicas, el imponente espectáculo que sobrecoge, anonada.

\footnotetext{
"Sección bibliográfica", El arte tipográfico, septiembre, 1919, p. 76.

"Sección bibliográfica", El arte tipográfico, septiembre, 1919, p. 76.

"Sección bibliográfica", El arte tipográfico, septiembre, 1919, p. 75.

"Sección bibliográfica", El arte tipográfico, enero, 1927, p. 144.

"Las importancia de las pequeñeces en la Imprenta", El arte tipográfico, enero, 1927, p. 130
} 
¡No hay nada igual en el mundo!"41 En la misma sección, contrastando el colorido y la religiosidad de la América hispana con la árida y racional aportación de la América sajona al progreso de la región, se reseñaban libros como Steps in industry and Testing before investing, abriendo paso a la parte esencial del mensaje que a la National y a los voceros del panamericanismo les interesaba consolidar: la construcción de un espacio donde el capitalismo estuviera a salvo.

\section{The American way of doing business}

Las revistas de la National conformaron un puente de divulgación que canalizó a los empresarios latinoamericanos conocimientos sistematizados sobre los avances en la metodología para lograr un negocio próspero. También abrieron un espacio publicitario para conectar a los productores con los consumidores promoviendo las lindezas del progreso. Con ellas, la empresa procuró exportar prácticas de la cultura estadounidense de los negocios. El punto de partida de los métodos empresariales de esta compañía surgía del corazón de una ética norteamericana que pretendia asegurar el progreso:

La mayoria de los hombres -decía una de sus publicaciones- ven los negocios como algo prosaico, un asunto circunscrito por órdenes y utilidades [...] Sin embargo es un juego con un tinte tan romántico como se puede encontar con cualquier otra búsqueda. Los negocios son el gran romance americano. Por la visión de los negocios y la poesía que conlleva su alma, los Estados Unidos se han convertido en la gran potencia mundial en menos de un siglo y medio. (A CHAPTER IN THE ROMANCE, 1921, p. 5).

Los elementos centrales de esta cultura empresarial consistian en lograr una buena organización, enfocarse plenamente en el cliente, y poner atención en la publicidad, centrada en el anuncio gráfico, y en las estrategias para cerrar "la venta". Resalta las particularidades del proceso moderno de producción: la importancia de los pequeños detalles como la limpieza y la organi- zación para propiciar el ahorro. Un buen negocio -recomendaban- se mantenía con higiene, orden y el abatimiento de costos que incrementaba la ganancia. Además de la calidad del producto, era necesario asegurar la puntualidad de entrega, educar a los operarios, de ahí que se diera importancia a las escuelas técnicas.

El artículo titulado "La cosa más sensible del mundo: nuestra cartera" enuncia un decálogo estratégico que llevaba implícita la necesaria frugalidad que exigian los negocios modernos:

El comerciante, lo mismo que el fabricante, tienen que velar mucho por su cartera. Está expuesta a ser presa de todos los vicios morales: la extravagancia, el desorden, el descuido, la deshonra, la inmoralidad. [...] Un mal sistema, un empleado descuidado, una máquina defectuosa, son tan salteadores como los bandidos de los caminos. ${ }^{42}$

Otro activo de los negocios modernos era la velocidad: la organización del tiempo y el espacio, la planeación para evitar riesgos y lograr la máxima rapidez en la producción. Se insistió en la retórica de la perfección del trabajo y la capacitación cotidiana del trabajador para ganar cada vez más utilidades. ${ }^{43}$ Para los ejecutivos de la National, la venta se basaba en el valor de la confianza que se construía con el comercio de productos que permitían lograr un trabajo de calidad y, como consecuencia, daba una estructura perdurable al negocio. La esencia de la confianza, lo que en inglés abarca el concepto de "trust" también se posicionó como un valor implícito en el andamiaje que haria posible el panamericanismo. Junto con las máquinas y el papel, la National y los fabricantes que representaba, exportaron a América Latina los valores de esta fórmula para la eficacia incuestionable del business estadounidense. Viajaron imágenes y conceptos que definian al hombre de negocios como hombre de acción que "rompe las cadenas del temor, la pereza y la vacilación".44 Esto -decía la publicidad panamericanista de la National- no le era ajeno al hombre latinoamericano:

\footnotetext{
"Sección bibliográfica", El arte tipográfico, enero, 1927, p. 144.

"La cosa más sensible del mundo: nuestra cartera", El arte tipográfico, abril, 1918, p. 282.

3 "Las importancia de las pequeñeces en la Imprenta", El arte tipográfico, enero, 1927, p. 130

44 "El hombre de acción", El arte tipográfico, marzo, 1916, p. 275.
} 
Ninguna otra empresa -explicaban los directores ha tratado con mayor número de esa clase de hombres (hombres de iniciativa y energia) que la National Paper and Type Company entre sus clientes de la América Latina, hombres que dan un mentís al dicho de que el latinoamericano todo lo deja "para mañana." ${ }^{45}$ [...] Ese hombre creativo, era de carácter práctico, emprendedor y estaba destinado al éxito. Dondequiera hay una mina para el hombre de imaginación e iniciativa. ${ }^{46}$

Este discurso dio un paso hacia la apreciación de los "otros americanos" pero transitó por la equiparación positiva con el anglosajón. Aunque significó un importante progreso para fortalecer los lazos entre el proveedor y los consumirdores, siguió manifestando un fuerte dejo de superioridad.

Se trató de difundir e implantar una metodología entre los vendedores que tratan al cliente como una presa. La National celebró la creación de una "Escuela preparatoria para maestros de la venta al por menor" en las aulas de la Universidad de Nueva York enfocada al trabajo práctico de la venta. Compartía con sus cilentes lationamericanos este gran logro:

Se analizaran -anunciaba en las páginas de su revista- varios métodos tipicos de venta y habrá debates libres sobre los principios relativos a la naturaleza humana, en su aplicación a una operación comercial entre parroquiano y vendedor. Se darán además cursos de nociones generales de ciencia, aritmética comercial, teoría y uso de los colores, dibujo y también lecciones de lenguaje y conversaciones comerciales.

Comprobado como lo está que un vendedor sin preparación alguna es uno de los mayores obstáculos para la venta al por menor, se procurará por todos los medios posibles hacer un vendedor consumado, conocedor de todos los secretos del arte de la venta. Hay verdadero ahorro de tiempo y de irritación nerviosa en saber el dependiente cómo ofrecer con prontitud y tacto los artículos que se desean, [...]. 47

El arte de la publicidad fue el centro nodal de esta la revolución comercial del siglo veinte. Con ella se redujo la distancia entre el vendedor y el consumidor, se transmitieron simbolos y se crearon necesidades. El vínculo entre el escri- tor, el buen cajista que diseñaba el anuncio y el vendedor cerraba el candado comercial. El panamericanismo fue posible por el desarrollo de las técnicas publicitarias donde impresores y editores se conjuntaron en un esfuerzo común. (WALKER, 1998, p. 185). Bajo el título "Los productos Norteamericanos les Rinden Lucro a los Editores latinoamericanos", la National presentaba con detalle "la doctrina norteamericana que demuestra que el anuncio paga". 48 "El anuncio -decía- reduce los gastos de vender, aumenta la producción, produce un costo más bajo". Aprender a cultivar estas técnicas era de suma importancia para los editores latinoamericanos con una visión empresarial:

\begin{abstract}
Un editor -recomendaba- tiene que sacar su ganancia principal de los anuncios. Si dicho editor es un prudente hombre de negocios. tratará por cuantos medios estén a su alcance de aumentar el número de anuncios que aparezcan en su periódico. [...]

Dondequiera que se vendan efectos norteamericanos, alli también se anuncian. Esta es una ley a que deseamos dar el mayor énfasis. Todo editor que haga lo posible por aumentar en su territorio las ventas de efectos norteamericanos, seguramente cosechará los beneficios de su trabajo en la forma de más y mayores anuncios. Los norteamericanos son anunciantes incurables. 49
\end{abstract}

Los anuncios que seguian esta filosofia partian de preguntas elementales suponiendo una total ignorancia por parte del comprador, se utilizaban íconos estadounidenses adaptados a un mercado latinoamericano mayormente rural, se tropicalizaron las estrategias de mercadotecnia para adaptarlas a situaciones cercanas a nuestra realidad. La publicidad cerraba el círculo necesario para que el panamericanismo aterrizara de un plano discursivo abstracto a un intercambio económico tangible: los editores latinoamericanos dependientes de maquinaria y de ingresos por publicidad serían un vehículo para ampliar el mercado de los productos estadounidenses. En el camino, allanó el camino para que el público

\footnotetext{
45 "El hombre de acción", El arte tipográfico, marzo, 1916, p. 275.

Hill, Napoleón, "La maquina más maravillosa del mundo", El arte tipográfico, septiembre, 1917, p. 40.

"Preparación universitaria para vendedores", El arte tipográfico, octubre, 1919, p. 109.

"Los productos norteamericanos les rinden lucro a los editores latinoamericanos", El arte tipográfico, julio, 1917. p. 1.

"Los productos norteamericanos les rinden lucro a los editores latinoamericanos", El arte tipográfico, julio, 1917, p. 1.
} 
hiciera suyos los valores del American Way of Life. La National concebía la calidad del anuncio como una fuente de luz e información. Recomendaba, por ejemplo, la elegancia tipográfica para propiciar mejores ventas. El anuncio, se decía, tenía un gran porvenir en Hispanoamérica. Era, por consecuencia, materia prima del panamericanismo. Tanto en la América del norte como en la del sur, "el poder del anuncio - decian - ha venido a ser una de las mayores fuerzas en el mundo de los negocios".50 Los editores y hombres de negocios estadounidenses contemplaban la "cuestión del anuncio" con toda formalidad y "velaban con solícito afán por el buen renombre del anuncio americano".51

[...] el anuncio, a semejanza de todo negocio, ha de descansar en la buena fe, ha de inspirarse en todo y por todo de la verdad. La divisa de este nuevo organismo se resume en esta palabra: "Verdad". [...] La antorcha del anuncio debe alumbrar con la verdad, y los editores de Pan América se deben a si mismos, a sus lectores y a sus respectivos paises el hacer cuanto puedan para que asi sea. ${ }^{2}$

Pasó a ser entonces, parte fundamental de la esfera pública transnacional que vinculó a las dos Américas:

Los hombres de negocios de los Estados Unidos están dando mayor y mayor desarrollo a sus operaciones en Hispano América, y sabido es que el anuncio forma parte integral de la propaganda comercial americana. Con el aumento del esfuerzo comercial americano no hay duda de que se iniciarán grandes campañas provechosas también para los editores de la América española lo que estimulará el interés por el valor comprobado de la obra y del método del anuncio. ${ }^{53}$

La National no abandonó el instinto paternal de educar abonando en la parte material para construir una prensa que era "fuente de luz para ilustrar la opinión".54 Esgrimió un proyecto pedagógico comercial donde el panamericanismo se lee como una empresa cultural. En esta empresa se ayudó de dos herramientas: la fuerza de la prensa y el periodismo y una especie de evangelización publicitaria de la ética estadounidense de los negocios. Cabe aún preguntarnos si la National es una empresa suigeneris en relación con este discruso de buena voluntad hacia el resto de las Américas o una de muchas. Su trayectoria y su particular nicho sirven de para comprender mejor cómo se vincularon los productores estadounidenses con el mercado latinoamericano. Es posible que la lógica de entendimiento mutuo desde un punto de vista cultural se haya repetido en otros casos.

Aunque el periodismo moderno en América Latina prosperó bajo un esquema de dependencia material del poderoso vecino del norte, podemos asegurar que el movimiento de las rotativas y las imprentas permitió la aceleración y la difusión de la cultura escrita que llevó en las primeras décadas del siglo veinte un agitado tono de efervescencia. Al colocarse del lado amable de la penetración yanqui en América Latina, aquella que reconoció a los otros como sujetos con los que podía darse la posibilidad de un intercambio, la National fomentó la creación de ese espacio abierto entre las naciones que no pasaba por las limitantes dimplomáticas ni militares: la esfera pública transnacional.

\section{Bibliografía}

A CHAPTER in the romance of trade. National $A$ sketch of its formation, aims, ideals and progress, 1900-1920. New York City: National Paper \& Type, 1921.

A NEW Pan-Americanism. The Advance, p. 1318, 18 Jun. 1914.

ADDINGTON, Bruce. The United States a world Power. Outlook, p. 796, 3 Apr. 1909.

BURKE Peter; BRIGSS, Asa. De Gutemberg a internet. Una historia social de los medios de comunicación. México: Taurus-Alfaguara, 2006.

CÁNDIDA Smith Richard. Improvised continent: Pan-Americanism and cultural Exchange. Philadelphia: University of Pennsylvania Press, 2017. DOI: https:// doi.org/10.9783/9780812294651

CONVENTION week at the capital. The Independent, 10 Jan., p. 68, 1916.

\footnotetext{
"El Periodismo es antorcha del progreso", El arte tipográfico, septiembre, 1919, p. 68

"El Periodismo es antorcha del progreso", El arte tipográfico, septiembre, 1919, p. 69.

"El Periodismo es antorcha del progreso", El arte tipográfico, septiembre, 1919, p. 69

"Gran porvenir para el anuncio en Hispanoamérica", El arte tipográfico, octubre, 1919, p. 107.

"El Periodismo es antorcha del progreso", El arte tipográfico, Septiembre,1919, p. 68.
} 
DAVIS H., Roberto. Soy la Prensa Tipográfica. El Arte Tipográfico. Revista Mensual dedicada al adelanto de la Imprenta y de las Artes Gráficas en General, Nueva York, t. XVII, n. 3, p. 74, sep. 1919.

DON JULíaN Ramos Peñasco. El Arte Tipográfico: Revista Mensual dedicada al adelanto de la Imprenta y de las Artes Gráficas en General, Nueva York, t. XVII, n. 3, p. 69, sept. 1919.

EL HOMBRE de acción. El Arte Tipográfico: Revista Mensual dedicada al adelanto de la Imprenta y de las Artes Gráficas en General, Nueva York, t. XIII, n. 9, 275, mar. 1916.

EL PERIODISMO es antorcha del progreso en el Panaricanismo. El Arte Tipográfico: Revista Mensual dedicada al adelanto de la Imprenta y de las Artes Gráficas en General, Nueva York, t. XVII, n. 3, 68, sept. 1919.

FOMENTO de las Relaciones de Amistad. El Arte Tipográfico: Revista Mensual dedicada al adelanto de la Imprenta y de las Artes Gráficas en General, Nueva York, t. XVII, n. 3, 106-107, sep. 1919.

GALLARDO NIETO, Galvarino. Panamericanismo. Santiago de Chile: Nascimento, 1941

GRAN PORVENIR para el anuncio en Hispanoamérica. El Arte Tipográfico: Revista Mensual dedicada al adelanto de la Imprenta y de las Artes Gráficas en General, Nueva York, t. XVII, n. 4, 107, oct. 1919.

HABERMAS, Jürgen. The structural transformation of the public sphere: an inquiry into a category of bourgeois society. Cambridge: MIT Press, 1991.

HILL, Napoleón. La maquina más maravillosa del mundo. El Arte Tipográfico: Revista Mensual dedicada al adelanto de la Imprenta y de las Artes Gráficas en General, Nueva York, t. XV, n. 3, p. 38, sept. 1917.

LA COSA más sensible del mundo: nuestra cartera. El Arte Tipográfico: Revista Mensual dedicada al adelanto de la Imprenta y de las Artes Gráficas en General, Nueva York, t. XV, n. 10, p. 282, abr. 1918

LA HUELGA de los operarios. El Arte Tipográfico: Revista Mensual dedicada al adelanto de la Imprenta y de las Artes Gráficas en General, Nueva York, t. XVII, n. 4, p. 97-98, oct. 1919 .

LA PUNTUALIDAD. El Arte Tipográfico: Revista Mensual dedicada al adelanto de la Imprenta y de las Artes Gráficas en General, Nueva York, t. XIII, n. 8, p. 235, feb. 1916.

LAS IMPORTANCIA de las pequeñeces en la Imprenta. El Arte Tipográfico: Revista Mensual dedicada al adelanto de la Imprenta y de las Artes Gráficas en General, Nueva York, t. XXIV, n. 3, 130-131, enero. 1927.

LE GRAND, Catherine C. Living in Macondo. Economy and culture in a United Fruit Company Banana Enclave in Colombia. In: JOSEPH Gilbert M.; LEGRAND, Catherine; SALVATORE, Ricardo D. (org.). Close encounters of empire. Writing the cultural history of U.S. - Latin American Relations. Durham: Duke University Press, 1998. p. 333368. DOI: https://doi.org/10.1215/9780822396352-010

LECTORES, clientes y amigos. El Arte Tipográfico: Revista Mensual dedicada al adelanto de la Imprenta y de las Artes Gráficas en General, Nueva York, t. XV, n. 7. p. 161, enero. 1918.
LOS PRODUCTOS norteamericanos les rinden lucro a los editores latinoamericanos. El Arte Tipográfico: Revista Mensual dedicada al adelanto de la Imprenta y de las Artes Gráficas en General, Nueva York, t. XV, n. 1, p. 1, jul. 1917.

MORENO, Julio. Yankee don't go home. Mexican nationalism, American business culture, and the shaping of modern Mexico, 1920-1950. Chapel Hill: The University of Carolina Press, 2003.

MÚJICA, J. Panamericanismo. Boletín de la Académia Chilena, p. 115, 1 enero. 1942.

PAN-AMERICAN Action at Buenos Ayres. Zion's Herald, p. 997, 10 Aug. 1910.

PETERS, Bernhard. National and transnational Public Spheres. En GRIPSRUD, Jostien, The idea of the public sphere. A reader. Plymouth: Lexington Books, 2010, p. 237-246.

PREPARACIÓN universitaria para vendedores. El Arte Tipográfico: Revista Mensual dedicada al adelanto de la Imprenta y de las Artes Gráficas en General, Nueva York, t. XVII, n. 4. p. 109, oct. 1919.

PRESIDENT Wilson's Message, The Independent, $\mathrm{p}$. 461, 20 Dec. 1915

ROCCO, Raymond; GARCIA, Fernando. Transnationalism: Issues and Perspectives. Madrid: Editorial Complutense, 2006

SE NECESITA un muchacho. El Arte Tipográfico: Revista Mensual dedicada al adelanto de la Imprenta y de las Artes Gráficas en General, Nueva York, t. XIII, n. 8, p. 235-236, feb. 1916

SECCIÓN bibliográfica. El Arte Tipográfico: Revista Mensual dedicada al adelanto de la Imprenta y de las Artes Gráficas en General, Nueva York, t. XVII, n. 3, p. 75, sept. 1919

SOME PAN-AMERICAN Problems. The New York Times, p. 50, 23 Jul. 1922.

VASCONCELOS, José. Panamericanism or Hispanoamericanism, Books Abroad, v. 5, n. 4, p. 437, oct. 1931. DOI: https://doi.org/10.2307/40070505

VERTOVEC, Steven, Transnationalism. New York: Routledge, 2009. DOl: https://doi.org/10.4324/9780203927083

LAIRD, Pamela Walker. Advertising progress. American business and the rise of consumer marketing. Baltimore: The Johns Hopkins University Press, 1998.

\section{Ana María Serna}

Doctora en Historia de América Latina por la Universidad de Chicago. Investigadora do Instituto de Investigaciones Dr. José María Luis Mora (Instituto Mora), México. Libros: "Dolo y Malicia". Regulación del lenguaje, criminalización del periodismo y libertad de expresión en México, 1901-1931, México, Instituto Mora-Tirant lo Blanch. (En Prensa). "Se solicitan reporteros". Historia oral del periodismo mexicano en la segunda mitad del siglo XX. México, Instituto Mora, 2015. Manuel Peláez y la vida rural en la Faja de Oro. México, Instituto Mora, 2009. 


\section{Dirección}

Ana Maria Serna

Instituto de Investigaciones Dr. José María Luis Mora

Plaza Valentin Gómez Farias, Square \# 12 Col. San Juan

Mixcoac, 03730

Ciudad de México, Distrito Federal, México 